UCRL-ID- 119709

\title{
Radiometer Measurements and Modeling of Ultraviolet Radiation at LLNL
}

\author{
*Donald J. Wuebbles, *Kenneth O. Patten, Jr., and †Allen S. Grossman \\ tLawrence Livermore National Laboratory \\ 7000 East Avenue, L-262 \\ Livermore, California 94550
}

and

*University of Illinois

Department of Atmospheric Sciences

105 S. Gregory Avenue

Urbana, Illinois 61801

January 1995

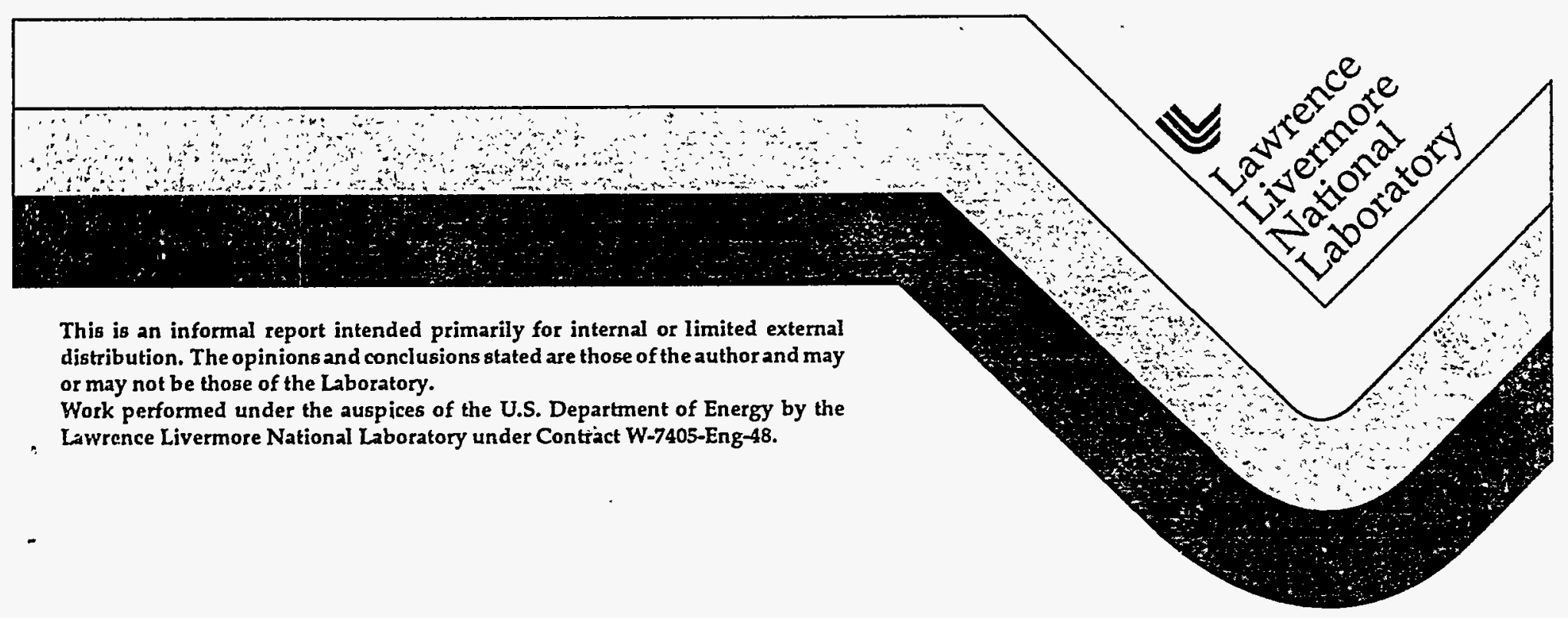




\section{DISCLAMER}

This document was prepared as an account of work sponsored by an agency of the United States Government. Neither the United States Croverument nor the University of Califomia nor any of their employees, makes any warranty, express or implied, or assumes any legal liability or responsibility for the accuracy, completeness, or usefulness of any information, apparatus, product, or process disclosed, or represents that its use would not infringe privately owned rights. Reference herein to any specific commercial product, process, or service by trade name, trademark, manufacturer, or otherwise, does not necessarily constitute or imply its endorsement, recommendation, or favoring by the United States Government or the University of California. The views and opinions of authors expressed herein do not necessarily state or reflect those of the United States Covernment or the University of California, and shall not be used for advertising or product endorsement purposes.

This report has been reproduced directly from the best available copy.

Available to DOE and DOE contractors from the Office of Scientific and Technical Information P.O. Box 62, Oak Ridge, TN 37831

Prices available from (615) 576-8401, FTS 626-8401

Available to the public from the National Technical Information Service

U.S. Department of Commerce 5285 Port Royal Rd. Springfield, VA 22161 


\section{DISCLAIMER}

Portions of this document may be illegible in electronic image products. Images are produced from the best available original document. 


\title{
Radiometer Measurements and Modeling of Ultraviolet Radiation at LLNL
}

\author{
Donald J. Wuebbles, Kenneth O. Patten, Jr., and Allen S. Grossman \\ Global Climate Research Division \\ Lawrence Livermore National Laboratory
}

\begin{abstract}
Measurements of atmospheric column ozone, from both satellite- and ground-based instruments, have revealed a trend of decreasing ozone amounts with time over the last few decades [WMO, 1991; IPCC, 1994]. One of the most important expected effects of this change is an increase in the flux of ultraviolet radiation at wavelengths between 280 and $320 \mathrm{~nm}$, known as ultraviolet-B or UV-B, at the Earth's surface. Changes in the ultraviolet at these wavelengths have important implications for the health of humans and the biosphere. In order to measure this effect, and in order to establish LLNL as a center for atmospheric measurements, the UV-B flux at LLNL was measured from November 1991 until the lead authors on this project left LLNL in August 1994 (Dr. Wuebbles and Dr. Patten are now at the University of Illinois where Dr. Wuebbles is head of the Department of Atmospheric Sciences).
\end{abstract}

In the measurements made at LLNL, a radiometer was used to collect total radiation for wavelengths from 280 to $350 \mathrm{~nm}$. The radiometer response increases markedly for wavelengths below $310 \mathrm{~nm}$; its spectral response is designed to be similar to that for erythema in human skin. The primary instrument used in these measurements was on special loan to LLNL from scientists in New Zealand and is the same instrument used in the New Zealand UV-B measurement network. In addition, two other instruments were loaned to LLNL over the last year by major instrument suppliers in the U.S. as testbeds for the new technology being produced by these companies. Measurements from one of these instruments were made in 1994, while the other instrument was in the process of being setup when Dr. Wuebbles decided to leave LLNL. The New Zealand instrument is in the process of being returned for recalibration before comparisons will be made to measurements made during 1991-1994 in New Zealand. While the final re-calibration of this radiometer is not yet available, some results of these measurements can be presented and discussed below. In addition, another important aspect of the project was the development of a new modeling capability by Dr. Grossman at LLNL for understanding of the UV-B reaching the Earth's surface. Several analyses from this model are also discussed below.

\section{UV-B Measurements}

UV-B flux on clear days is found in the LLNL measurements to vary with time of day in accord to that expected from consideration of the solar zenith angle. The flux increases as solar zenith angle decreases from early morning to local noon plus or minus up to 30 minutes, then decreases with increasing solar zenith angle during afternoon hours. The asymmetry of the UV-B intensity between times in the morning and in the afternoon with identical solar zenith angles has been noted in previous measurements in England. These measurements, however, have noted a seasonal dependence in this asymmetry: little asymmetry exists in June or December; afternoon intensities are higher than morning in March; and morning intensities higher than afternoon in September. The mechanism, whether physical or chemical, responsible for this asymmetry is currently uncertain and is still being analyzed. Part of it certainly has to do with aerosol concentrations and scattering, but there are no independent measurements available to verify this.

Prior studies have indicated that clouds are expected to block UV-B radiation from reaching the ground. In the UV-B measurements at LLNL, most clouds are observed to do exactly that, particularly on days of heavy cloud cover. The resulting diurnal plot of UV-B flux versus time efficiently identifies cloudy days which are then excluded from further analysis. However, particularly in cases of light cloud cover, UV-B fluxes greater than those found on clear days are observed. This is due to reflection of light from the clouds, which creates additional paths besides direct transmission by which UV-B may reach a given point on the ground.

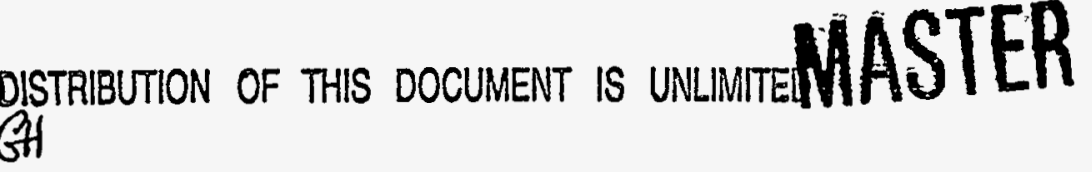


Plotting diurnal average or diurnal maximum UV-B against time of year shows that the intensity varies markedly with time of year. Peak intensities occur on or several days after the Summer Solstice, while intensity minimum occurs at or slightly after the Winter Solstice. This is as expected: the solar zenith angle at local noon ranges from a minimum of $13^{\circ}$ on the Summer Solstice to a maximum of $59^{\circ}$ on the Winter Solstice at Livermore.

In March 1992, UV-B intensities on the 22nd reached values considerably higher than those on days immediately preceding or following. We obtained ozone column data from the Total Ozone Mapping Spectrometer project at NASA Goddard to determine whether a minimum of ozone coincided with this maximum in UV-B intensity. The ozone column, however, was not significantly less on the 22nd, and no recurrence of such a maximum was observed. None of our analyses were able to further clarify this anomaly, although we have speculated that an unusual pattern of partial cloudiness may have increased the scattering of solar radiation to the radiometer.

Diurnal maximum UV-B intensities for 1993 were observed, in terms of radiometer response, to be significantly lower than those in 1992. This seems consistent with the recovery of total ozone columns from historic minima in 1991 and 1992 created by the eruption of Mount Pinatubo. However, as mentioned above, the re-calibration of this radiometer is not as yet available and will be necessary to furthering the analysis of the data obtained in 1993 and 1994. UV-B radiometers of this design are well known to suffer response degradation over timescales of one year or more. Thus, we cannot currently provide conclusions at this time on the several year UV-B flux trends made at LLNL (this should be available in early-1995 and we still hope to get a journal paper out of our studies). For similar reasons, we cannot at this time provide conclusions regarding our UV-B flux comparison with measurements by Gerald Smith in Auckland, New Zealand.

In July 1993, a comparison between the radiometer and a UV spectrophotometer operated by Tom Crabtree of the Electro-Optic Characterization Facility was performed on a clear day. The spectrophotometer response, when convoluted with the initial spectral response curve obtained for the radiometer before the start of the measurements, was a factor of at least two higher at six different times of day. This result serves as potential confirmation that a radiometer response change occurred.

A successful long-term UV-B radiation monitoring effort at LLNL would require special support: a combination of several well-calibrated UV-B radiometers with at least one calibrated UV spectrophotometer is required, and visible light monitoring as a means of quantifying clouds would be highly desirable in order to isolate possible ozone column effects on UV-B. Measurements of aerosols are also needed. Dr. Wuebbles was working on establishing such measurement system at LLNL.

\section{UV-B Modeling}

The surface fluxes in the wavelength range $175 \mathrm{~nm}$ to $735 \mathrm{~nm}$ have been calculated at altitudes between 0 and $80 \mathrm{~km}$ (Grossman et al. 1993). This spectral range covers the UV-B wavelength region, $250-350 \mathrm{~nm}$. Validation of the LLNL model against published UV-B surface flux calculations indicate agreement to within approximately 5 percent. Calculations have also been made to determine the effects of a uniformly mixed aerosol layer of thickness $1 \mathrm{~km}$, at the Earth's surface, on the UV-A and UV-B fluxes (Grossman and Grant, 1994). Both a rural and an urban aerosol model were used. The results show that for a visibility change from $95 \mathrm{~km}$ to $15 \mathrm{~km}$ the UV-B fluxes were attenuated by approximately 14 percent for the rural aerosol layer and approximately 23 percent for the urban aerosol layer. Similar results were obtained in the UV-A spectral region.

The input parameters to the radiative transfer model are profiles of pressure, temperature, trace gas mixing ratios, solar zenith angle, and at each wavelength, surface albedo, total single scattering albedo, total asymmetry factor, and exo-atmospheric solar flux. Ozone absorption, 
acrosols, and Rayleigh scattering are the major sources of atmospheric extinction in the atmosphere. A two stream flux model is used to calculate the diffuse irradiance on each atmospheric layer. The sources of the upwards and downwards diffuse irradiance, due to scattering from the direct beam, are obtained by the use of a delta-Eddington approximation. The single layer treatment for incident diffuse irrradiance is treated by the Sagan-Pollack model for the diffuse reflection and transmission factors. The radiative transfer equations for the atmosphere model have been solved for the fluxes at each level using an adding method.

The aerosol model used consisted of a bimodal size distribution composed of $30 \%$ dust like material and $70 \%$ wáter soluble material at $70 \%$ relative humidity for the rural aerosol case. The urban model consisted of the rural model mixed with a soot-like carbonaceous material in the proportion of $80 \%$ and $20 \%$ respectively. The dry air optical properties were mixed with the water optical properties using a volume weighted average of the two material at the appropriate relative humidity. The optical properties of this mixture were then used as the input to a Mie scattering calculation to determine the extinction coefficient, single scattering albedo, and asymmetry factor at each wavelength. The aerosol scattering properties were combined with the atmospheric gas scattering properties at each level using an optical depth weighted average.

\section{REFERENCES}

Grossman, A. S., and K. E. Grant, 1994: The effects of tropospheric aerosols on surface UV radiation, LLNL Report UCRL-ID-118059.

Grossman, A.S., Grant, K.E., and D.J. Wuebbles, 1993: Radiative flux calculations at UV and visible wavelengths, LLNL Report UCRL-ID-115336.

Intergovernmental Panel on Climate Change (IPCC): Climate Change; The IPCC Scientific Assessment, Cambridge University Press, Cambridge, UK, 1994.

World Meteorological Organization, 1991: Scientific Assessment of Ozone Depletion: 1991, Global Ozone Research and Monitoring Project Report 25, Geneva.

\section{CONTRIBUTED PAPER}

Grossman, A. S., and K. E. Grant, 1994: The effects of tropospheric aerosols on surface UV radiation, LLNL Report UCRL-JC-118055-ABS. Presented at Fall Meeting of AGU, San Francisco, Calif., December 1994. 